\title{
Maternal Modeling and the Acquisition of Fear and Avoidance in Toddlers: Influence of Stimulus Preparedness and Child Temperament
}

\author{
Kathrin Dubi • Ronald M. Rapee • Jane L. Emerton • \\ Carolyn A. Schniering
}

Published online: 13 December 2007

(C) Springer Science + Business Media, LLC 2007

\begin{abstract}
The aim of the present study was to investigate the influence of maternal modeling on the acquisition of fear and avoidance towards fear-relevant and fear-irrelevant, novel stimuli in a sample of 71 toddlers. Children were shown a rubber snake or spider (fear-relevant objects) and a rubber mushroom or flower (fear-irrelevant objects), which were alternately paired with either negative or positive expression by their mothers. Both stimuli were presented again after a 1- and a 10-min delay, while mothers maintained a neutral expression. The toddlers showed increased fear and avoidance of the objects following negative reaction from their mothers than following positive maternal expression. This was similarly true for both fearrelevant and fear-irrelevant stimuli. In addition, no association was found between child temperament and behavioral responses and a weak association emerged between child temperament and emotional responses. The results demonstrate that young children can rapidly form conditioned emotional and behavioral responses via maternal reactions regardless of stimulus preparedness or child temperament. It
\end{abstract}

This research was conducted as part of a doctoral dissertation by Kathrin Dubi.

\section{K. Dubi $(\bowtie)$}

Department of Psychology, University of Basel,

Missionsstrasse 60/62,

4055 Basel, Switzerland

e-mail: kathrin.dubi@unibas.ch

R. M. Rapee $\cdot$ C. A. Schniering

Department of Psychology, Macquarie University,

Sydney, Australia

J. L. Emerton

Department of Psychology, University of Bath,

Bath, UK is suggested that early maternal modeling may be relevant to a broad spectrum of fearful reactions.

Keywords Fear · Maternal modeling · Toddlers .

Stimulus preparedness $\cdot$ Temperament

\section{Introduction}

Anxiety disorders are the most prevalent class of emotional disorders in both adults (Andrews et al. 1999; Kessler et al. 1994) and children (Bernstein et al. 1996; Fergusson et al. 1993; Verhulst et al. 1997). Models of childhood anxiety disorders integrate several factors and processes such as biology (e.g., genetics, psychophysiology, temperament), behavior (e.g., operant, observational, and respondent learning models), interpersonal factors (e.g., attachment theory, parent/child interaction), and cognition (e.g., information processing, stimuli/situation interpretation) (Hudson and Rapee 2004; Rapee 2001; Weems and Stickle 2005). A number of authors have pointed to modeling as an important factor in the development of fear and anxiety in children (Muris and Merckelbach 2001; Muris et al. 1996; Rapee 2001; Weems and Stickle 2005). According to Rapee's model, children are likely to acquire anxious behavior following observation of parents (or significant others) acting in a fearful or anxious manner towards specific stimuli. Moreover, such fear learning is expected to occur more extensively in a child who is born with a vulnerability to anxiety (e.g., inhibited temperament). In addition, opportunities for modeling of fearful behaviors are more likely with anxious parents who show anxious behavior more frequently (Muris et al. 1996).

Traditionally, clinicians have made a distinction between fear and anxiety. According to Lang et al. (2000), fear is a 
reaction to a specific threatening stimulus, resulting in escape or avoidance when cue proximity increases. Anxiety, however, is characterized by a more general, diffuse, and longer lasting state of distress, prompted by less explicit or more generalized cues. Anxiety involves increased physiological arousal but does not necessarily lead to organized functional behavior. Throughout this paper, we mainly use the terms "fear" and "fearful" because we look at the mechanisms in a specific modeling episode where mothers provide informational and emotional cues about a particular object (fear) and not about a diffuse range of situations (anxiety).

The significance of modeling as a method to acquire anxiety has been suggested by previous authors (e.g., Rachman 1977, 1991). According to Rachman, vicarious acquisition through observational learning or modeling is one of three distinct pathways to anxiety, the other two being direct conditioning experiences and information/ instruction. Evidence for Rachman's three pathways has been reviewed broadly (e.g., King et al. 1998; Merckelbach et al. 1996). Moreover, these reviews support the view that, while direct conditioning is predominantly connected to clinical phobias, observational learning and exposure to negative information more often contribute to mild fears (Muris and Merckelbach 2001). Following Rachman's suggestion, a number of studies have examined the role of modeling of stimulus-threat associations in the acquisition of specific fears. Most of these studies have focused on adults and relied on retrospective self-reports (e.g., Ehlers 1993; Menzies and Clarke 1995; Öst 1987; Öst and Hugdahl 1981; Watt and Stewart 2000; Watt et al. 1998; for a review see Merckelbach et al. 1996). These studies support the role of modeling, with a small but consistent number of patients reporting their fears to have begun following observation of threat in the presence of a particular stimulus. However, the development of fearful behavior is likely to be far too complex and subtle to be assessed via retrospective report (Gerull and Rapee 2002) and it is assumed that the critical onset of development of many fears is early in life (Öhman 1986; Öst 1987). In addition, Rapee (2001) has noted that anxiety disorders are often preceded by a vulnerable temperament that manifests during the first few years.

Preliminary studies using questionnaires with children have similarly shown fear acquisition following observation of stimulus-threat associations by the use of retrospective self-reports. Questionnaires given to children or their parents indicate that a consistent percentage of children attribute the onset of their fears to modeling experiences (Menzies and Clarke 1993; Merckelbach et al. 1996; Ollendick and King 1991). Nevertheless, as with adult studies, this research is also limited by the use of retrospective self-reports and the reliance on insight for what is likely to be a subtle and complex process.

Few studies have involved direct observation of vicarious conditioning of fear reactions or avoidance behavior using controlled laboratory procedures. In an early series of studies, Bandura and colleagues found clear, short-term effects of observational learning in both adults and children (Bandura et al. 1969, 1967; Bandura and Rosenthal 1966). Although the majority of these studies were aimed at demonstrating fear reduction via modeling rather than at fear acquisition, results provide some evidence that brief, conditioned emotional reactions can be acquired through observation.

Some of the strongest evidence supporting observational learning of fear was provided by Mineka, Cook, and colleagues (Cook and Mineka 1989, 1990; Mineka and Cook 1993; Mineka et al. 1984) who demonstrated clear acquisition of fear in response to fear-relevant stimuli in rhesus monkeys following exposure to a fearful model (using either live models or representations on video). Importantly, Cook and Mineka $(1989,1990)$ demonstrated that such vicarious fear acquisition only occurred in response to fear-relevant stimuli (e.g., toy snake, toy crocodile) and not to fear-irrelevant stimuli (e.g., flower, toy rabbit). Given the consistency with theories of clinical phobias, this finding provided a clear link between these laboratory demonstrations of vicarious fear acquisition and models of clinical disorders.

More recently, several studies have begun to demonstrate acquisition of fearful reactions in human toddlers in response to novel stimuli following negative expressions from another person, most commonly their mother (De Rosnay et al. 2006; Egliston and Rapee 2007; Gerull and Rapee 2002; Murray et al. in press). For example, Gerull and Rapee (2002) demonstrated that 17-month-old toddlers showed greater fear and avoidance towards a toy spider or snake following negative reactions from their mothers relative to those shown following positive reactions. Moreover, this effect was maintained up to 10 min later. More recent research has shown that young children can acquire a fear of strangers when observing fearful reactions in their mothers (De Rosnay et al. 2006; Murray et al. in press). In a study with 7-9-year-old children, Field et al. (2001) presented two types of information about novel stimuli (two monsters): video information and verbal information in the form of a story. Whereas children's self-reported fear beliefs increased significantly as a result of verbal information, the increase of fear beliefs was not significant when the information was given via video which showed an adult female acting fearfully/avoidant towards the novel toy monster. Other studies have also shown that verbal threat information has a highly significant effect on 
children's fear beliefs about and avoidance of novel animals and social situations (Field 2006; Field et al. 2003; Field and Lawson 2003; Muris et al. 2003). In a recent study by Askew and Field (2007) children's fear beliefs (selfreported and indirectly measured with affective priming) increased for novel animals paired with scared faces. These changes persisted for 1 week when measured explicitly and up to 3 months when measured indirectly with affective priming. In addition, a behavioral task showed that children were slower to approach an animal they had seen paired with faces expressing fear.

One issue of central importance to contemporary theories of the origins of fears and phobias is how to account for the nonrandom distribution of the objects that are associated with fear (e.g., Marks 1987; McNally 1987; Mineka 1985; Öhman 1986; Öhman et al. 1985; Seligman 1971). Research has focused on the interrelated concepts of preparedness and selective associations. According to Seligman (1971), humans have a phylogenetically based predisposition (preparedness) to rapidly acquire fears of certain situations or objects that are probabilistically associated with species specific dangers. Thus for example, in humans it is suggested that fears will be more rapidly acquired and less easily extinguished in response to representations of snakes or spiders than to flowers or mushrooms (see reviews by Mineka and Öhman 2002; Öhman 1993; Öhman et al. 2000; Öhman and Mineka 2001). Laboratory evidence has largely supported these claims (e.g., Öhman 1986; Öhman et al. 1985, 1975, 1976), although evidence for enhanced fear acquisition in response to prepared stimuli has been considerably less consistent than evidence for reduced extinction (McNally 1987).

Previous research into the vicarious acquisition of fears in human toddlers has been characterized by a reliance on what would be considered fear-relevant (prepared) stimuli. These have included toy snakes, or spiders, or human strangers. To date, only two studies have used fearirrelevant (unprepared) stimuli (Gunnar and Stone 1984; Hornik et al. 1987). Twelve to thirteen-month old children were presented with one pleasant, one ambiguous, and one aversive toy, while their mother reacted with positive and then neutral expressions (Gunnar and Stone 1984) or either positive, negative, or neutral, and then neutral expressions (Hornik et al. 1987). The results were inconsistent in terms of toddlers' reactions towards pleasant, ambiguous, and aversive objects. Whereas Gunnar and Stone (1984) only found a significant effect of maternal expression for the ambiguous toy but not for the fear-relevant or the fearirrelevant toy, Hornik et al. (1987) found more positive responses and more approach towards the pleasant toy than towards the ambiguous and aversive toys. Therefore, fear acquisition effects have not been demonstrated in response to fear-irrelevant stimuli. Future studies need to establish whether fear can be acquired in response to fear-irrelevant stimuli and whether these fears would be lost more rapidly than those in response to fear-relevant stimuli.

A second issue of potential importance to vicarious acquisition of feared associations is the role of temperamental vulnerability. As described earlier, there has been considerable interest in the possibility that certain early temperament styles - in particular behavioral inhibitionrepresent a precursor to the development of anxiety disorders (Kagan et al. 1984, 1987; Neal et al. 2002; Prior et al. 2000; Rapee and Spence 2004). The term behavioral inhibition describes a relatively consistent pattern of behavioral and emotional responses to unfamiliar or novel people, places/situations, or objects (Kagan et al. 1984). Typically, inhibited children react to novel situations with initial caution, restraint, low rates of approach, and quiet withdrawal and they are usually shy, timid, and reticent with unfamiliar people (Belsky and Park 2000). Models of the development of anxiety argue for a central role of temperament in guiding the child's interactions with the world (Hudson and Rapee 2004; Rapee 2001). Specifically, it is proposed that threat associations will be more easily acquired and less easily extinguished in those who are temperamentally vulnerable to anxiety (Hudson and Rapee 2004). To date there has been little investigation of this assumption. De Rosnay et al. (2006) used a social referencing paradigm to establish the association between infant temperamental fearfulness and the development of social anxiety in infants. Twelve to 14-month old infants observed their mothers interacting with a stranger in either a socially anxious or a non-anxious manner and then interacted with the stranger themselves. High fear infants were more avoidant in the socially anxious condition than low fear infants.

In summary, very few studies have investigated the effects of maternal affective modeling on children's fear and avoidance using both fear-relevant and fear-irrelevant stimuli. In addition, only one study to date has assessed the importance of temperament in the acquisition of fear via modeling (De Rosnay et al. 2006). Therefore, the aim of the present study was to investigate the role of maternal modeling in the acquisition of fear and avoidance in young children and to determine whether the fear-relevance of an object and the child's inhibition status influenced the magnitude and length of this effect. Toddlers were shown one fear-relevant and one fear-irrelevant stimulus in the presence of either a positive or negative expression from their mother. To investigate the persistence of the effect once the mother ceases to deliver the affective message, the stimuli were again presented after 1 and $10 \mathrm{~min}$ with a 
neutral maternal response. Replicating the design of Gerull and Rapee (2002), toddlers' affective responses and approach/avoidance were assessed during the modeling phase (positive/negative maternal expression) and again at 1- and 10-min intervals (neutral maternal expression). It was predicted that toddlers would show greater fear and avoidance in the presence of their mother's negative expression and that this would be greater for fear-relevant than for fear-irrelevant stimuli. Further, it was predicted that fearfulness in response to the fear-relevant stimuli would persist for up to $10 \mathrm{~min}$, while any fearfulness to the fearirrelevant stimuli would reduce before this time. It was also expected that inhibited toddlers would show stronger effects compared with less inhibited children.

\section{Materials and Methods}

\section{Participants}

Analyses were based on a sample of 71 toddlers and their mothers, recruited through newspaper advertisements and day care centers in Sydney, Australia. Mothers interested in participating in the study were asked to call the university for more information and to schedule an appointment. To compensate for time and effort, mothers received \$20 in cash and children a small age-appropriate toy. All toddlers were healthy, full-term, and from English-speaking or bi-lingual families. The children ranged from 15 to 20 months of age, with a mean of $17.39(S D=1.83)$ months. The age range of the study was influenced by findings that by the end of the first year of life the infant is capable of evaluating stimuli and events using the emotional responses of others (Gunnar and Stone 1984). The sample consisted of 44 girls $(62 \%)$ and 27 boys (38\%). The ethnic composition of the sample was 73\% Anglo-Saxon, 7\% Italian, 6\% Asian, 3\% Israeli, 3\% Greek, and $8 \%$ other European. Most of the children $(88.7 \%)$ were from two-parent families. Fifty-nine percent of toddlers did not have a sibling, $30 \%$ had one sibling, $8 \%$ had two siblings, and 3\% had four or more siblings. Mothers were in general well educated with $89 \%$ having attained tertiary qualifications at a university or college. As assessed on the Depression Anxiety Stress Scales (Lovibond and Lovibond 1995a), mothers' mean level of depression was $3.97(S D=4.09)$, their mean level of anxiety was $3.38(S D=2.96)$, and their mean level of stress was $11.10(S D=6.08)$, all within the normal range (Lovibond and Lovibond 1995a). Internal reliabilities for the depression and for the stress scale (each seven items) was good (Cronbach's $\alpha=0.80$ and 0.74 , respectively), internal reliability for the anxiety scale (seven items) was poor (Cronbach's $\alpha=0.46$ ). As assessed on the Approach/With- drawal subscale of the Short Temperament Scale for Toddlers (Prior et al. 1987; Sewell et al. 1988), the participating toddlers had a mean of $2.60(S D=1.09)$, which is lower (more bold/approaching) than the Australian norm for this age group (population mean= 3.07; Prior et al. 1987; Sewell et al. 1988). Internal reliability for the temperamental scale (five items) was very good (Cronbach's $\alpha=0.92$ ).

Measures and Materials

Stimuli The experimental stimuli consisted of four novel rubber toys. Two of the objects were fear-relevant stimuli, one was a curled black and red rubber snake $(22 \mathrm{~cm}$ diameter) with open jaws, and the other was a black, white, and red rubber spider (13 $\mathrm{cm}$ diameter). Spiders and snakes are commonly feared animals and are theoretically held to be biologically prepared for fear conditioning (Cook et al. 1986; Seligman 1971; reviews by Öhman 1979, 1993; Öhman and Mineka 2001). The other two objects were fearirrelevant stimuli (Cook et al. 1986; reviews by Öhman 1979, 1993; Öhman and Mineka 2001), a brown and white mushroom $(15 \mathrm{~cm}$ height $)$ and a white and green flower (20 cm height). The choice of the stimuli used for the present study was influenced by earlier studies using similar or identical objects or pictures of these stimuli (Cook et al. 1986; Dimberg 1986; Egliston and Rapee 2007; Gerull and Rapee 2002; reviews by Öhman 1979, 1993; Öhman and Mineka 2001). According to mothers' reports, none of the children had previously seen the toys used in the study and none of them had displayed fear responses towards any of the stimuli.

Demographic Questionnaire Mothers were asked to provide details of their child's age, sex, number of siblings, and ethnic background. In addition, information about mother's age, family status, highest level of education, occupation, and use of day care programs were obtained.

Toddlers' Temperament To assess the toddlers' general tendency to be shy/anxious or confident the Approach/ Withdrawal subscale of the Short Temperament Scale for Toddlers, an Australian adaptation of the Toddler Temperament Scale (Fullard et al. 1984) was used. Items on the scale relate to the child's emotional and behavioral responses and the ease, tempo, and type of adjustment to unfamiliar people or situations. Test-retest reliability (2 weeks) of the Approach/Withdrawal scale has been reported to be 0.90 and the internal consistency (alpha coefficient) to be 0.84 (Prior et al. 1987; Sewell et al. 1988). Additionally, the Approach construct has shown moderate to high stability from infancy to 8 years of age (Pedlow et al. 1993). 
Depression Anxiety Stress Scales short version (DASS21) As research has shown that parental anxiety or depression can affect their children's emotional state and behavior (Capps et al. 1996; Pine et al. 2005; Weems and Stickle 2005), maternal anxiety, depression, and stress/tension was measured to control for a possible influence of mothers' psychopathology using the DASS21, a short version of the DASS (Lovibond and Lovibond 1995a). The DASS21 is a self-report instrument with high internal consistency and validity (Antony et al. 1998; Brown et al. 1997; Lovibond and Lovibond 1995b).

\section{Manipulations}

All toddlers were successively shown the four stimuli. Two objects, one fear-relevant (either spider or snake) and one fear-irrelevant (either mushroom or flower) were used in the baseline trial to assess the toddlers' responses to the stimuli in the absence of prior experience. The other two objects were employed in the remaining trials and were each alternately paired with a different emotion modeled by the mothers. The pairings of stimulus toys and the respective emotions were counterbalanced between participants. In addition, the order of presentation and the application of the stimuli for either baseline or experimental trial were counterbalanced between participants (resulting in 16 combinations).

Maternal expressions of fear and disgust as well as happiness were encouraged, taught, and practised before and during the experiment. A fear/disgust blend was included as recent research suggests that both emotions tend to be present in an interactive, aggregate manner upon exposure to phobic stimuli (Sawchuk et al. 2002). Furthermore, acquisition of spider fear has been found to be particularly facilitated by parental disgust reactions when confronted with spiders (De Jong et al. 1997). The mothers' emotional modeling included facial and vocal expressions as well as gesturing. In both the positive and the negative condition mothers were instructed and encouraged to show their child how they felt about the stimulus toys, verbally and via facial expression and gestures. Mothers were asked to avoid emotional words but to describe the objects in a positive or negative way and to indicate how nice or how ugly the toy was, while exhibiting the appropriate facial and body expression. They were told not to name the objects or to directly instruct their child using explicit behavioral directions (e.g., 'Don't touch' or 'Come over here'). This was done in order to prevent confounding the effect of modeling with compliance with instructions. In the neutral condition mothers were instructed to remain silent and as expressionless and blank as possible.
Procedure

The study has been approved by the Ethics Review Committee at Macquarie University. Prior to the experimental session mothers were mailed the information and consent forms and the questionnaire measures. The experiment was conducted in a laboratory-playroom at Macquarie University, Sydney. The child, the mother, and the toy stimulus were positioned in a triangular arrangement. The toddlers' starting position was from a play mat about $1.5 \mathrm{~m}$ from the stimulus and the same distance from the mother. The toys were at arms-length from the mother. Floor markings demarcated the area where the stimuli would be presented and where the mother and child were to be seated. This was to guarantee the maintenance of the standardized triangular arrangement for each mother child-pair.

The test session began with a brief period of free play with age-appropriate toys placed on the play mat to allow the toddlers to adjust to the experimental room. While the toddlers were playing on their own, mothers were familiarised with the experimental procedure and trained on the emotional displays (fearful/happy) in a different part of the experimental room. In this way, children were able to settle into the new environment while their mothers were explained the procedure. To provide a strong test of the modeling hypothesis under the most naturalistic condition possible and since Baldwin and Moses (1994) suggested that infants will be less confused about the topic of an emotional communication if they are given strong and clear referential cues, multiple cues (gaze and action) were used. The mothers were given suggestions on appropriate corresponding comments (e.g., 'Wow, it's so brown' or 'Uh, it's so black') and facial and body expressions. They were instructed to display the facial expression, gestures, and sentences as soon as they uncovered the stimulus toy and to hold that expression for $30 \mathrm{~s}$. In addition, mothers were given a copy of the instructions for reference during the trials ${ }^{1}$. To assess the most externally valid reaction of the child toward the toy, toddlers were not restricted from touching the experimental stimuli (Gerull and Rapee 2002; Gunnar and Stone 1984; Hornik and Gunnar 1988; Hornik et al. 1987). In cases where toddlers picked up the stimuli, mothers were told to put the object back on the floor and to continue to

\footnotetext{
${ }^{1}$ At this stage, the mothers were only instructed and given written suggestions on how to display appropriate emotions but these instructions and suggestions were not paired with any of the stimuli. Moreover, the names of the stimuli were not mentioned at any time, the mothers and the experimenter did not face the toddlers, and the stimuli were disguised in the box. Consequently, it is very unlikely that any incidental learning (via hearing or seeing) could have occurred.
} 
maintain the designated emotional expression. After the introductory period the mothers placed their child on the play mat, opposite the concealed stimulus toy, and returned to their chair.

Baseline Trial To assess the toddlers' responses to both fear-relevant and fear-irrelevant stimuli in the absence of prior experience, one fear-relevant and one fear-irrelevant stimulus were shown. The mothers were instructed to pose and maintain a neutral facial expression (described as plain face, not expressing any emotion) and to remain silent as soon as the stimulus toy was presented. The first stimulus was presented for $30 \mathrm{~s}$, followed by $1 \mathrm{~min}$ free play, then the second stimulus was presented for $30 \mathrm{~s}$. The mothers then again engaged their child in talk or play for $1 \mathrm{~min}$. The order and choice of the objects were randomized and counterbalanced. Table 1 provides an example of the order and presentation of the four stimuli across trials for one participant.

Observational Conditioning Trial During the observational conditioning trial the second of the fear-relevant and the fear-irrelevant stimuli were shown. The mothers captured their child's attention by saying 'Let's see what's under this box' and then uncovered the third stimulus. When the toy was exposed, the mothers reacted with either a positive or negative expression for $30 \mathrm{~s}$, while alternating their gaze between their child and the stimulus. Afterwards, the stimulus was covered and the child was engaged in $1 \mathrm{~min}$ free play. Then the mothers lifted the box again, gaining the child's attention and held a neutral expression. The toy was

Table 1 Example of the order and presentation of the four stimuli across trials for one participant

\begin{tabular}{lcc}
\hline Trial & Stimulus & $\begin{array}{c}\text { Maternal } \\
\text { expression }\end{array}$ \\
\hline Baseline 1 & $\begin{array}{c}\text { Fear-relevant: } \\
\text { spider }\end{array}$ & Neutral \\
Baseline 2 & $\begin{array}{c}\text { Fear-irrelevant: } \\
\text { mushroom }\end{array}$ & Neutral \\
& $\begin{array}{l}\text { Fear-relevant: } \\
\text { Observational conditioning } \\
\text { trial (modeling) }\end{array}$ & Negative \\
$\begin{array}{c}\text { Observational conditioning } \\
\text { trial (1-min delay) }\end{array}$ & $\begin{array}{c}\text { Fear-relevant: } \\
\text { snake }\end{array}$ & Neutral \\
Observational conditioning & Fear-irrelevant: & Positive \\
trial (modeling) & flower & \\
Observational conditioning & Fear-irrelevant: & Neutral \\
trial (1-min delay) & flower & \\
Follow-up trial & Fear-relevant: & Neutral \\
(10-min delay) & snake & \\
$\begin{array}{c}\text { Follow-up trial } \\
\text { (10-min delay) }\end{array}$ & Fear-irrelevant: & Neutral \\
\hline
\end{tabular}

covered after $30 \mathrm{~s}$. After 1 min of free play, which was introduced to prevent any emotional carry-over from the previous toy, the fourth stimulus was presented and the mothers displayed the opposite emotional expression. This procedure was repeated for the fourth stimulus.

Follow-up Trial Following the two modeling and 1-min delay trials the toddlers had $10 \mathrm{~min}$ of free-play. Afterwards, the children were presented again with the third and the fourth stimuli, in the same order as the initial trial, while the mothers held a neutral expression. The final two presentations were again separated by a 1-min delay.

\section{Data Recording and Coding}

All experimental sessions were videotaped using two wall mounted cameras. One camera recorded the child's behavior and facial expression while the other was focused on the facial expression of the mother.

Two trained raters working independently coded all toddlers' emotional and behavioral responses and all mothers' facial expressions from the videotapes. Scales adapted from previous research (Egliston and Rapee 2007; Gerull and Rapee 2002; Repacholi 1998) were used for the ratings. Toddlers' emotional response toward the stimulus toy was rated on a five-point scale from obvious fear of the toy $(-2)$ through sober, neutral expression (neither positive nor negative emotions present, 0) to high positive affect, broad smile $(+2)$. The toddlers' behavioral response was rated on a five-point scale from -2 (avoidance/retreat, indicated by approach to mother, physical contact with mother, etc.) through 0 (neither approach nor avoidance) to +2 (approach, indicated by approach towards toy, touching and exploring toy, etc.). Mothers' emotional expression (including verbal, facial, and body expression and gestures) was coded in order to check the experimental manipulation. The scale ranged from -2 (strong fear/disgust) through 0 (neutral expression, neither fear/disgust nor happy/ encouraging expression) to +2 (very happy/encouraging).

Inter-rater reliabilities for ratings of the mothers' emotional expression and the children's emotional and behavioral response were calculated for all toddler-mother pairs. Cohen's kappa for the mothers' emotional expression ranged from $K=0.66$ to 1.0 (mean $K=0.88$ ), for the children's emotional response from $K=0.43$ to 0.70 (mean $K=0.56$ ), and for their behavioral response from $K=0.73$ to 0.86 (mean $K=0.77$ ). These reliability estimates indicate a moderate (children's emotional response) to excellent (mothers' emotional expression and children's behavioral response) level of coding agreement (Fleiss 1981). In order to provide the most reliable data (Shrout and Fleiss 1979), 
the individual ratings of the two raters were collapsed and a mean value was computed.

Based on ratings of the mothers' affective response and children's emotional and behavioral response, data from nine toddler-mother pairs were excluded: Three toddlers were considered not to be fully engaged with the task, two toddlers became distressed during testing, two mothers did not follow instructions correctly, and two were excluded due to technical problems with the video recording. The excluded participants did not differ significantly from the included participants on demographics, infant temperament, or on maternal levels of depression, anxiety, and stress (all $p \mathrm{~s}>0.05$ ).

\section{Results}

\section{Overview of Statistic Analyses}

Before proceeding with the main analyses, correlations and one-way-analyses of covariance (ANCOVA) were conducted to determine any influence of toddlers' or mothers' characteristics. Paired $t$-tests were then conducted to analyse toddlers' emotional and behavioral responses at baseline. For the main analyses, toddlers' mean emotional and behavioral response scores across time in reaction to mothers' emotional expression were subjected to a 2 (stimulus: fear-relevant, fear-irrelevant) $\times 2$ (mothers' expression: positive, negative) $\times 3$ (time: modeling, 1-min delay, 10-min delay) repeated measures ANCOVA including toddlers' level of inhibition (continuous variable) as a covariate. $^{2}$ To further analyze significant main effects or interactions, follow-up $t$-tests were conducted.

\section{Preliminary Analyses}

There was no significant association between attendance at child care programs and the children's emotional $(r=-0.14$, NS) or behavioral response ( $r=-0.14$, NS) across the three times. Similarly, toddlers' age was not significantly associated with emotional $(r=-0.07$, NS) or behavioral response $(r=-0.15$, NS). There was no association between mothers' depression ( $r=0.07$, NS), anxiety $(r=0.03$, NS), and stress $(r=0.01, \mathrm{NS})$ levels and toddlers' emotional

\footnotetext{
$\overline{2}$ The order and choice of the fear-relevant and fear-irrelevant objects were randomized and counterbalanced between participants. However, the researchers checked for any possible influence of order of modeling condition (positive or negative modeling first) and of type of stimulus (flower, mushroom, snake, or spider). Few interactions were significant and these were difficult to interpret. As there were no significant interactions with the variables of interest, order of modeling and type of stimulus were not considered any further.
}

response. In addition, there was no significant association between mothers' levels of depression $(r=-0.03$, NS), anxiety $(r=-0.08$, NS), and stress $(r=-0.11$, NS) and toddlers' behavioral response. Using an ANCOVA controlling separately for each subscale of the DASS21, the toddlers did not differ significantly with respect to the degree of their emotional response (for depression level $F(1,69)=0.35$, NS, for anxiety level $F(1,69)=0.06$, NS, for stress level $F(1,69)=0.01, \mathrm{NS})$ or their behavioral response (for depression level $F(1,69)=0.05$, for anxiety level $F(1,69)=0.50$, NS, for stress level $F(1,69)=0.84$, NS), demonstrating that the children's emotional and behavioral responses were not influenced by mothers' levels of depression, anxiety, or stress.

Child care attendance, age, and maternal levels of depression, anxiety, and stress were not included in the main analysis because of their low relationship with toddlers' emotional and behavioral response and because they were not subjects of the hypotheses.

\section{Toddlers' Emotional and Behavioral Response at Baseline}

The analysis of toddlers' emotional and behavioral responses at baseline (neutral maternal display) showed no significant differences between reactions towards the fearrelevant and the fear-irrelevant objects, $t(70)=0.00$, NS for emotional expression and $t(70)=-0.17$, NS for approach $/$ avoidance behavior. Toddlers' mean emotional response towards the fear-relevant object was $0.52(S D=0.68)$, and towards the fear-irrelevant object was $0.52(S D=0.58)$. Toddlers' mean behavioral response towards the fearrelevant stimulus was $1.1(S D=0.95)$, and towards the fear-irrelevant stimulus was $1.1(S D=0.86)$.

\section{Toddlers' Emotional Response}

Toddlers' mean emotional response scores across time in reaction to mothers' emotional expression are shown in Table 2. There was a significant main effect of mothers' emotional expression with greater fear shown following negative maternal expressions than positive, $F(1,68)=$ 11.93, $p<0.01$, but no significant main effects for time, $F(2,136)=2.72$, NS, stimulus, $F(1,68)=2.45$, NS, or temperament $F(1,68)=3.63$, NS. There was a significant interaction between toddlers' temperament and time $F(2,68)=3.43, p<0.05$, but no significant interactions of stimulus by time, $F(2,136)=1.27$, NS, stimulus by expression, $F(1,136)=0.07$, NS, expression by time, $F(2,136)=1.81$, NS, or expression by temperament, $F(2,136)=2.03$, NS. Importantly, the three way interaction between emotional expression, stimulus, and time was not significant, $F(2,136)=0.54$, NS, nor was the three way interaction between emotional expression, temperament, 
Table 2 Mean (SD) emotional and behavioral response scores across time in response to mothers' positive versus negative expressions

\begin{tabular}{|c|c|c|c|c|c|c|}
\hline & \multicolumn{2}{|l|}{ Modeling trial } & \multicolumn{2}{|l|}{ 1-min delay } & \multicolumn{2}{|l|}{ 10-min delay } \\
\hline & Emot. response & Beh. response & Emot. response & Beh. response & Emot. response & Beh. response \\
\hline Mothers' positive expression & $0.75(0.64)$ & $1.35(0.86)$ & $0.56(0.74)$ & $1.11(1.07)$ & $0.40(0.81)$ & $0.97(1.11)$ \\
\hline Mothers' negative expression & $-0.04(0.70)$ & $0.47(1.20)$ & $0.25(0.78)$ & $0.84(1.11)$ & $0.32(0.75)$ & $0.94(1.11)$ \\
\hline
\end{tabular}

Higher emotional scores $=$ stronger positive affect. Higher behavioral scores $=$ stronger approach $($ Range: -2 to +2$)$.

and time, $F(2,136)=0.21$, NS. Effect sizes for all three measuring times and for both fear-relevant and fearirrelevant stimuli were small to medium, ranging from $r=0.02$ to $r=0.21$. To further analyze the significant interaction between toddlers' temperament and time, toddlers were split into two temperamental groups along the median (2.40) and follow-up $t$-tests were conducted. The participating toddlers had a mean temperament score of $2.60(S D=1.09)$, the mean temperamental scores for the low and high behavioral inhibition groups were 1.80 $(S D=0.53)$ and $3.48(S D=0.83)$, respectively. The difference between the two temperament groups approached significance with positive maternal expression at the 10 -min delay, $t(69)=1.98, p=0.051$, indicating that the more bold/approaching toddlers demonstrated less fear in response to positive expression from the mother than to her negative expression at the 10-min delay.

\section{Toddlers' Behavioral Response}

Toddlers' mean behavioral response scores across time in reaction to mothers' emotional expression are shown in Table 2. There was a significant main effect of mothers' emotional expression with greater avoidance shown following negative maternal expressions than positive, $F(1,68)=4.35, p<0.05$, and of stimulus, $F(1,68)=4.23$, $p<0.05$, but no significant main effects for time, $F(2,136)=$ 0.23 , NS, or temperament, $F(1,68)=0.26$, NS. No significant interactions of stimulus by time, $F(2,136)=$ 0.47 , NS, stimulus by expression, $F(1,136)=0.01$, NS, expression by time, $F(2,136)=1.04$, NS, expression by temperament, $F(2,136)=0.38$, NS, or time by temperament, $F(2,136)=0.19$, NS, were found. Notably, the three way interaction between emotional expression, stimulus, and time was not significant, $F(2,136)=0.95$, NS, nor was the three way interaction between emotional expression, temperament, and time, $F(2,136)=0.51$, NS. Effect sizes for all three measuring times and for both fear-relevant and fear-irrelevant stimuli were small to medium, ranging from $r=0.09$ to $r=0.25$. Follow-up $t$-tests were used to further analyze the main effect of stimulus. These showed that toddlers demonstrated significantly greater avoidance toward the fear-irrelevant stimulus than to the fearrelevant, $t(69)=-2.14, p<0.05$.

\section{Discussion}

As predicted, the main results of the study showed that mothers' affective responses towards novel objects influenced their child's subsequent reactions to that stimulus. In general, toddlers showed more fearful emotional expressions and less approach behavior when their mothers reacted negatively to the toy than when they acted positively. This finding is consistent with previous results showing that expression of fear and/or disgust by the mother in the presence of a novel object resulted in avoidance behavior on behalf of her child relative to an object to which the mother expressed positive emotions (De Rosnay et al. 2006; Gerull and Rapee 2002; Hornik et al. 1987; Klinnert 1984; Mumme et al. 1996).

However, when interpreting these results, toddlers' emotional and behavioral responses across time need to be examined more closely. The mean scores in Table 2 look as though the differences in toddlers' responses towards negative and positive maternal expression might become less over time. In order to get a more differentiated understanding, separate $t$-tests were run at each time point for toddlers' emotional and behavioral responses. The fear and avoidance shown by the toddlers in response to the negatively paired stimulus persisted for $1 \mathrm{~min}$, as did the positive emotions and approach behavior in response to mothers' encouraging expression. However, in contrast to the findings of Gerull and Rapee (2002), the effects in the present study did not persist over the length of the whole trial - they became less pronounced and disappeared by the 10-min delay, whereas Gerull and Rapee (2002) found persisting, although less pronounced effects after 1 and 10 min. Similarly, Egliston and Rapee (2007) only found persistent effects for positive modeling in their study with toddlers showing rapid decay in conditioned fear responses between post-test and 20-min follow-up. Furthermore, although Hornik et al. (1987) found carryover effects in their social referencing study, the toddlers' responses were less pronounced after $8 \mathrm{~min}$ in the second trial. In addition, research conducted by Field and colleagues did not find consistent results on the lasting effects of vicarious learning. While an initial study (Field et al. 2001) failed to find an effect of vicarious learning, a more elaborated procedure (Askew and Field 2007) found effects that lasted 
1 week. However, these effects were relatively weak when compared to paradigms that used verbal information to change children's fears. Still, as the present study replicated the design of Gerull and Rapee's study, which found persistent, although less pronounced effects after 1 and $10 \mathrm{~min}$, the reasons for the diminished effects at the 10-min delay in this study remain unclear. It is possible that mothers' neutral reactions to stimuli just $1 \mathrm{~min}$ after the modeling task could have attenuated the previously conditioned emotional or behavioral reactions. However, this aspect replicated the same method as used in previous research and was necessary to demonstrate that the child actually learned something about the stimulus rather than simply reflected the mother's emotion. A more plausible explanation for the differences in results between studies may come from the fact that several toddlers in the current study touched and played with the stimuli during the trials. Given that direct personal experience is likely to be a more powerful source of information about threat than modeling, direct contact with the stimuli should very rapidly reduce their fearful properties. In this case, direct learning experiences could account for the diminished effects at the 10-min delay. In contrast to the current study and to the study of Gerull and Rapee (2002), the method used by Egliston and Rapee (2007) required stimuli to be withdrawn before toddlers had direct contact with them. Unfortunately, the report by Gerull and Rapee (2002) does not indicate what percentage of toddlers may have touched the stimuli and therefore it is possible that a smaller proportion of their children engaged in direct contact with the stimuli. Thus, it is not clear at this stage whether differences in direct contact with the stimuli may account for the differences in maintenance of fearfulness between studies, but this methodological issue certainly requires exploration, particularly as there is no consistency in the social referencing literature concerning this methodological problem. For instance, some authors (Gunnar and Stone 1984; Hornik and Gunnar 1988; Hornik et al. 1987; Moses et al. 2001) report that the toddlers in their studies were allowed to touch the stimuli whereas others (Blackford and Walden 1998; Klinnert 1984; Rosen et al. 1992) do not address this issue. Future studies should test the relative value of social referencing from the mother versus direct experience through touching as a source of learning information. Finally, given the inconsistent results in studies on vicarious learning, it is possible that learning through observation is a relatively weak pathway to develop fear compared to conditioning or verbal information, unless stimuli that are being observed are in themselves aversive such as in Mineka's work with primates (Mineka and Cook 1993; Mineka et al. 1984).

In terms of fear-relevance of stimuli, it was assumed that toddlers would show greater fear and avoidance toward fear-relevant stimuli than toward fear-irrelevant stimuli. However, analyses showed the opposite result. Yet, again, when interpreting these results, toddlers' emotional and behavioral responses across time and toward different stimuli need to be examined more closely. Detailed follow-up $t$-tests showed that toddlers' patterns of reactions toward the fear-relevant and fear-irrelevant stimuli were inconsistent across time, maternal expression, and stimulithe significant main effect of stimulus was mainly due to the fact that toddlers demonstrated greater avoidance toward the fear-irrelevant stimulus than to the fear-relevant, but only at the modeling trial and only in response to mother's negative expression. Still, the result of greater avoidance toward fear-irrelevant stimuli is not consistent with previous demonstrations in non-human primates of greater fear acquisition following vicarious conditioning to fear-relevant stimuli than to fear-irrelevant stimuli (Cook and Mineka 1989, 1990). One explanation for these differences may be the fact that the non-human primates were provided with up to 12 trials of modeled reactivity whereas toddlers in the present study only observed their mothers reacting emotionally during a single trial. Perhaps modeling using a greater number of mother reaction trials might allow differences between fear-relevant and fearirrelevant stimuli to emerge. Interestingly, consistent with research with primates, the finding that there were no significant differences between fear-relevant and fearirrelevant objects at the baseline trial provides evidence that toddlers may not react differently (emotionally or behaviorally) towards fear-relevant and fear-irrelevant stimuli in the absence of prior experience or maternal modeling. Moreover, effect sizes for fear-relevant and fearirrelevant stimuli proved to be small to medium. In contrast to the work with primates, research into the role of preparedness in humans has resulted in more mixed evidence (McNally 1987; Mineka and Öhman 2002). Overall, review of the importance of fear-relevance to conditioning has in some studies failed to support the suggestion that fear-relevant stimuli show more rapid acquisition of conditioned emotional reactions (McNally 1987). Hence the lack of consistent difference in the current study between modeled responses to the two types of stimuli are not incompatible with the broader human conditioning literature. However, research into human fear conditioning has generally indicated that fear-relevant stimuli support a longer maintenance of fearful responding than do fear-irrelevant stimuli (McNally 1987; Mineka and Öhman 2002; Öhman and Mineka 2001). The fact that fearful responding reduced by $10 \mathrm{~min}$ to a similar extent in response to both types of stimuli is inconsistent with the broader human conditioning literature. As described earlier the lack of continued responding at $10 \mathrm{~min}$ is inconsistent with previous findings (Gerull and Rapee 2002) and it is 
possible that certain methodological features of the study were responsible for this difference. However, one conclusion must be that this paradigm taps into processes that are different to those found in human phobic responses. More specifically, it is possible that the modeling paradigm used here reflects the learning of normal, general danger information. In other words, it may demonstrate one way in which mothers teach their children about the true dangers of the world and these processes may be different to those involved in the learning of irrational, excessive fears such as those demonstrated in phobic reactions. Furthermore, the choice of the fear-relevant and fear-irrelevant stimuli needs to be investigated more closely. As described, the vast majority of studies exploring vicarious conditioning of fear reactions used similar or identical objects or pictures of these stimuli (Cook et al. 1986; Dimberg 1986; Egliston and Rapee 2007; Gerull and Rapee 2002; McNally and Reiss 1982; Thunberg and Dimberg 2000; reviews by Öhman 1979, 1993; Öhman and Mineka 2001). Nevertheless, it is possible that the stimuli may not have been completely comparable in terms of familiarity, even to the young toddlers in our study. In discussing this with the mothers, a number of them pointed out that their child might be more familiar with flowers than with mushrooms. Consequently, the possibility of preexisting differences between these objects in degree of affective valence cannot be rigorously controlled as all human subjects - even children as young as 15 months - have almost certainly been exposed to both fear-relevant and fear-irrelevant stimuli similar to those used in the current study.

Theoretically, it was also expected that learning about threat from mothers would be more rapid and/or prolonged in children who were temperamentally vulnerable to anxiety compared with children without such vulnerabilities (Muris et al. 1996; Rapee 2001). The current results failed to demonstrate significant associations between children's temperament and their emotional and behavioral responses (aside from a small effect on affective reactions in uninhibited children after the 10-min delay), suggesting that behavioral inhibition may not influence instrumental learning of approach/avoidance behavior. This finding is in marked contrast to theories of the development of anxiety that posit an interaction between temperament and environmental factors such as modeling (e.g., Muris et al. 1996; Rapee 2001). However, the small effect at the 10-min delay - the more bold/approaching toddlers demonstrated less fear in response to positive expression from the mother than to her negative expression - suggests that temperament might play a role in instrumental learning of fear after a certain amount of time. It is possible that more trials or extended follow-up delays are needed to allow for differences in behavioral inhibition levels to emerge.
One of the limitations of the study is the restricted range of temperament scores among the toddlers. Toddlers in the current sample had a mean approach score of $2.60(S D=$ 1.09), which is lower (indicating less inhibition) than the Australian norm for this age group (population mean $=3.07$; Prior et al. 1987; Sewell et al. 1988). Since the study relied on volunteers, it is possible that mothers were more likely to participate when their child was bold and outgoing. This becomes especially apparent when analyzing the mean temperament score for the high behavioral inhibition group (3.48), which suggests only a moderate level of shyness. The failure to demonstrate a significant effect for temperament may in part be due to the lack of very shy toddlers participating in the study. An additional limitation is that the construct of approach as it is typically assessed may not have been the most relevant temperament construct to focus on. Most published forms of assessment of inhibition and approach tend to focus principally on social inhibition (e.g., Garcia-Coll et al. 1984; Kagan et al. 1984; Reznick et al. 1986). This is especially true of the measure used in the current study: Short Temperament Scale for Toddlers focuses entirely on items concerning unfamiliar people or places (Prior et al. 1987; Sewell et al. 1988). Given the physical threat nature of the fear-relevant stimuli used in the current study and even the physical nature of the information communicated by the mothers to their children regarding the fear-irrelevant stimuli, different results may have been demonstrated through use of a measure that included more physical threat-based aspects of inhibition (e.g., Bishop et al. 2003).

Inter-rater reliabilities in the current study for maternal emotional expression and toddlers' behavioral response were excellent and inter-rater reliability for toddlers' emotional response was moderate (Cicchetti and Sparrow 1981; Fleiss 1981). Facial expression proved more difficult to rate than originally anticipated. The video cameras were mounted high up and it was difficult to see the toddlers' facial expression when they were looking down or turning away from the camera. A hidden or disguised floor-mounted camera would have been more appropriate for recording children's facial expression. In addition, internal consistency was good for the depression and the stress scale of the DASS21 and poor for the anxiety scale. As previous studies have reported high internal consistency for all three scales (Antony et al. 1998; Brown et al. 1997; Lovibond and Lovibond 1995b), the poor internal reliability for the anxiety scale is unexpected. Taking a closer look at the means of the DASS21 in the present sample reveals that the mean levels of anxiety and depression were lower than in Lovibond's study (Lovibond and Lovibond 1995b), suggesting that the mothers in the present community sample were less anxious and less depressed compared to other community 
samples. Nevertheless, it remains unclear at this stage why the internal consistency of the anxiety subscale was poor. Importantly however, there were no significant associations between the DASS21-subscales and toddlers' emotional and behavioral responses.

This study makes an important contribution to the limited data on the development of fear. However, there are a number of other questions that need to be addressed. Although it was demonstrated that maternal modeling can contribute to the acquisition of fear reactions in early childhood, the extent to which these processes are consistent with those in the natural environment remain to be explored. The current study used a laboratory paradigm to examine the specific role of maternal modeling, fear relevance of stimuli, and child's temperament on a complex phenomenon. It is very likely that other factors also influence the development and persistence of fear. The validity of such a laboratory paradigm to the development of real fears requires future research in naturalistic settings. Given the inconsistent findings to date, additional studies are needed to further understand the possible interaction between temperament and fear conditioning events and the fear-relevance of stimuli. Similarly, the duration of the effects need to be further explored, as results in this area are inconsistent. Future work should look at the strength of the modeling as predictor of the length of time learnt responses persist. Another interesting area of research may relate to developmental or age differences in the acquisition of fear via modeling. In addition, it is possible that the learning experience via maternal modeling was confounded with verbal information, which is, as described earlier, another pathway to fear. Research shows that children as young as 10 months understand up to 145 words (Fenson et al. 1994), even if they don't talk yet. By the age of 18 months (the mean age of the study sample) the active vocabulary of a child contains about 50 words (Bloom 1998; Siegler et al. 2003). Even if the toddlers in this study did not receive specific negative or positive information about the novel stimuli from their mothers, there is a possibility that the use of verbalization by mothers during the modeling phase did influence the toddlers' emotional and behavioral responses via the information pathway. Finally, features of the model need to be elaborated. It needs to be established if young children learn most effectively from their mothers or if other models also support such effects. Research on social referencing suggests that any adult model (e.g., the experimenter) may support such effects (Hirshberg and Svejda 1990; Klinnert et al. 1986). However, data from Egliston and Rapee (2007) imply that the effects may be stronger in response to the primary caregiver.

In conclusion, this study provides further evidence for the importance of modeling in the acquisition of fear and avoidance to a wide range of stimuli in toddlers. The results clearly demonstrate that toddlers as young as 15 months can form short lasting associations to novel objects, including both fear-relevant and fear-irrelevant stimuli, based on a relatively brief affective reaction from their mother. Neither child temperament nor fear-relevance of the stimuli were found to be important predictors of fear acquisition and avoidance behavior relative to maternal modeling. These data have major implications for models of the development of specific phobia and other anxiety disorders. It appears that specific fears can be learned through modeling of a parent's affective reaction toward a novel stimulus. However, in most cases, mere observational learning is probably not enough to produce severe fear and avoidance behavior. In addition, according to Mineka and Zinbarg (1996), if vicarious learning is relevant for fear and phobia acquisition, responses need to endure. The types of stimuli which will support such learning and the duration for which these fears will persist still require investigation. In conjunction with the results of De Rosnay et al. (2006), Egliston and Rapee (2007), and Gerull and Rapee (2002), the findings suggest that the influence of the environment on later anxiety may begin in infancy via observational processes. The current study demonstrated that toddlers are sensitive to maternal emotions and modulate their own affective responses and behavior in line with such maternal expression. However, the results question whether the modeling paradigm truly provides a model of the development of anxiety disorders or whether it rather offers a model of the transmission of relatively brief and specific threat information from mothers to their toddlers.

Acknowledgments The research was supported by an overseas postgraduate research scholarship to Kathrin Dubi from the Swiss National Science Foundation and by grants of the Freiwillige Akademische Gesellschaft and the Theodor Engelmann Foundation.

\section{References}

Andrews, G., Hall, W., Teesson, M., \& Henderson, S. (1999). The mental health of Australians. Canberra, Australia: Commonwealth Department of Health and Aged Care.

Antony, M. M., Bieling, P. J., Cox, B. J., Enns, M. W., \& Swinson, R. P. (1998). Psychometric properties of the 42-item and 21-item versions of the Depression Anxiety Stress Scales (DASS) in clinical groups and a community sample. Psychological Assessment, 10, 176-181.

Askew, C., \& Field, A. P. (2007). Vicarious learning and the development of fears in childhood. Behaviour Research and Therapy, 45, 2616-2627.

Baldwin, D. A., \& Moses, L. J. (1994). Early understanding of referential intent and attentional focus: Evidence from language and emotion. In C. Lewis, \& P. Mitchell (Eds.), Children's early understanding of mind (pp. 133-156). Hillsdale, NJ: Erlbaum.

Bandura, A., Blanchard, E. B., \& Ritter, B. (1969). Relative efficacy of desensitization and modeling approaches for inducing behav- 
ioral, affective, and attitudinal changes. Journal of Personality and Social Psychology, 13, 173-199.

Bandura, A., Grusec, J. E., \& Menlove, F. L. (1967). Vicarious extinction of avoidance behavior. Journal of Personality and Social Psychology, 5, 16-23.

Bandura, A., \& Rosenthal, T. L. (1966). Vicarious classical conditioning as a function of arousal level. Journal of Personality and Social Psychology, 3, 54-62.

Belsky, J., \& Park, S. Y. (2000). Exploring reciprocal parent and child effects in the case of child inhibition in US and Korean samples. International Journal of Behavioral Development, 24, 338-347.

Bernstein, G. A., Borchardt, C. M., \& Perwien, A. R. (1996). Symptoms of anxiety disorders in normal children. Journal of the American Academy of Child and Adolescent Psychiatry, 29, $759-765$.

Bishop, G., Spence, S. H., \& McDonald, C. (2003). Can parents and teachers provide a reliable and valid report of behavioral inhibition. Child Development, 74, 1899-1917.

Blackford, J. U., \& Walden, T. A. (1998). Individual differences in social referencing. Infant Behavior and Development, 21, 89-102.

Bloom, L. (1998). Language acquisition in its developmental context. In D. Kuhn, \& R. S. Siegler (Eds.), Handbook of child psychology, Vol. 2 (Cognition, perception, and language. (5th ed.) pp. 309370. New York: Wiley.

Brown, T. A., Chorpita, B. F., Korotitsch, W., \& Barlow, D. H. (1997). Psychometric properties of the Depression Anxiety Stress Scales (DASS) in clinical samples. Behaviour Research and Therapy, $35,79-89$.

Capps, L., Sigman, M., Sena, R., Henker, B., \& Whalen, C. (1996). Fear, anxiety and perceived control in children of agoraphobic parents. Journal of Child Psychology, Psychiatry and Allied Disciplines, 37, 445-452.

Cicchetti, D. V., \& Sparrow, S. S. (1981). Developing criteria for establishing the interrater reliability of specific items in a given inventory. American Journal of Mental Deficiency, 86, 127-137.

Cook, E. W., Hodes, R. L., \& Lang, P. J. (1986). Preparedness and phobia: Effect of stimulus content on human visceral conditioning. Journal of Abnormal Psychology, 95, 195-207.

Cook, M., \& Mineka, S. (1989). Observational conditioning of fear to fear-relevant versus fear-irrelevant stimuli in rhesus monkeys. Journal of Abnormal Psychology, 98, 448-459.

Cook, M., \& Mineka, S. (1990). Selective associations in the observational conditioning of fear in rhesus monkeys. Journal of Experimental Psychology, Animal Behavior Processes, 16, 372-389.

De Jong, P. J., Andrea, H., \& Muris, P. (1997). Spider phobia in children: Disgust and fear before and after treatment. Behaviour Research and Therapy, 35, 559-562.

De Rosnay, M., Cooper, P. J., Tsigaras, N., \& Murray, L. (2006). Transmission of social anxiety from mother to infant: An experimental study using a social referencing paradigm. Behaviour Research and Therapy, 44, 1165-1175.

Dimberg, U. (1986). Facial reactions to fear-relevant and fearirrelevant stimuli. Biological Psychology, 23, 153-161.

Egliston, K.-A., \& Rapee, R. M. (2007). Inhibition of fear acquisition in toddlers following positive modelling by their mothers. Behaviour Research and Therapy, 45, 1871-1882.

Ehlers, A. (1993). Somatic symptoms and panic attacks: A retrospective study of learning experiences. Behaviour Research and Therapy, 31, 269-278.

Fenson, L., Dale, P. S., Reznick, J. S., Bates, E., Thal, D. J., \& Pethick, S. J. (1994). Variability in early communicative development. Monographs of the Society for Research in Child Development, 59 (Serial No. 242).
Fergusson, D. M., Horwood, L. J., \& Lynskey, M. T. (1993). Prevalence and comorbidity of DSM-III diagnoses in a birth cohort of 15 year olds. Journal of the American Academy of Child and Adolescent Psychiatry, 32, 1127-1134.

Field, A. P. (2006). The behavioral inhibition system and the verbal information pathway to children's fears. Journal of Abnormal Psychology, 35, 337-345.

Field, A. P., Argyris, N. G., \& Knowles, K. A. (2001). Who's afraid of the big bad wolf: A prospective paradigm to test Rachman's indirect pathways in children. Behaviour Research and Therapy, $39,1259-1276$.

Field, A. P., Hamilton, S. J., Knowles, K. A., \& Plews, E. L. (2003) Fear information and social phobic beliefs in children: A prospective paradigm and preliminary results. Behaviour Research and Therapy, 41, 113-123.

Field, A. P., \& Lawson, J. (2003). Fear information and the development of fears during childhood: Effects on implicit fear responses and behavioural avoidance. Behaviour Research and Therapy, 41, 1277-1293.

Fleiss, J. L. (1981). Statistical methods for rates and proportions (2nd ed.). New York: Wiley.

Fullard, W. B., McDevitt, S. C., \& Carey, W. B. (1984). Assessing temperament in one- to three-year old children. Journal of Pediatric Psychology, 9, 205-216.

Garcia-Coll, C., Kagan, J., \& Reznick, J. S. (1984). Behavioral inhibition in young children. Child Development, 55, 1005-1019.

Gerull, F. C., \& Rapee, R. M. (2002). Mother knows best: Effects of maternal modeling on the acquisition of fear and avoidance behavior in toddlers. Behaviour Research and Therapy, 40, 279-287.

Gunnar, M. R., \& Stone, C. (1984). The effects of positive maternal affect on infant responses to pleasant, ambiguous, and fearprovoking toys. Child Development, 55, 1231-1236.

Hirshberg, L. M., \& Svejda, M. (1990). When infants look to their parents: I. Infants' social referencing of mothers compared to fathers. Child Development, 61, 1175-1186.

Hornik, R., \& Gunnar, M. R. (1988). A descriptive analysis of infant social referencing. Child Development, 59, 626-634.

Hornik, R., Risenhoover, N., \& Gunnar, M. R. (1987). The effect of maternal positive, neutral, and negative affective communications on infant responses to new toys. Child Development, 58, $937-$ 944.

Hudson, J. L., \& Rapee, R. M. (2004). From anxious temperament to disorder: An etiological model of generalized anxiety disorder. In R. G. Heimberg, C. L. Turk, \& D. S. Mennin (Eds.), Generalized anxiety disorder: Advances in research and practice (pp. 51-74). New York: Guilford.

Kagan, J., Reznick, J. S., Clarke, C., Snidman, N., \& Garcia-Coll, C. (1984). Behavioral inhibition to the unfamiliar. Child Development, 55, 2212-2225.

Kagan, J., Reznick, J. S., \& Snidman, N. (1987). The physiology and psychology of behavioral inhibition in children. Child Development, 58, 1459-1473.

Kessler, R. C., McGonagle, K. A., Zhao, S., Nelson, C. B., Hughes, M., Eshleman, S., et al. (1994). Lifetime and 12-month prevalence of DSM-III-R psychiatric disorders in the United States: Results from the national comorbidity survey. Archives of General Psychiatry, 51, 8-19.

King, N. J., Gullone, E., \& Ollendick, T. H. (1998). Etiology of childhood phobias: Current status of Rachman's three pathways theory. Behaviour Research and Therapy, 36, 297-309.

Klinnert, M. D. (1984). The regulation of infant behavior by maternal facial expression. Infant Behavior and Development, 7, 447-465.

Klinnert, M. D., Emde, R. N., Butterfield, P., \& Campos, J. J. (1986). Social referencing: The infant's use of emotional signals from a 
friendly adult with mother present. Developmental Psychology, 22, 427-432.

Lang, P. J., Davis, M., \& Öhman, A. (2000). Fear and anxiety: Animal models and human cognitive psychophysiology. Journal of Affective Disorders, 61, 137-159.

Lovibond, S. H., \& Lovibond, P. F. (1995a). Manual for the Depression Anxiety Stress Scales (2nd ed.). Sydney: Psychology Foundation.

Lovibond, P. F., \& Lovibond, S. H. (1995b). The structure of negative emotional states: Comparison of the Depression Anxiety Stress Scales (DASS) with the Beck Depression and Anxiety Inventories. Behaviour Research and Therapy, 33, 335-342.

Marks, I. (1987). Fears, phobias, and rituals: Panic, anxiety, and their disorders. New York: Oxford University Press.

McNally, R. (1987). Preparedness and phobias: A review. Psychological Bulletin, 101, 283-303.

McNally, R., \& Reiss, G. (1982). The preparedness theory of phobias and human safety-signal conditioning. Behaviour Research and Therapy, 20, 153-159.

Menzies, R. G., \& Clarke, J. C. (1993). The etiology of childhood water phobia. Behaviour Research and Therapy, 31, 499-501.

Menzies, R. G., \& Clarke, J. C. (1995). The etiology of phobias: A nonassociative account. Clinical Psychological Review, 15, 23-48.

Merckelbach, H., De Jong, P. J., Muris, P., \& Van den Hout, M. A. (1996). The etiology of specific phobias: A review. Clinical Psychology Review, 16, 337-361.

Merckelbach, H., Muris, P., \& Schouten, E. (1996). Pathways to fear in spider phobic children. Behaviour Research and Therapy, 34, 935-938.

Mineka, S. (1985). Animal models of anxiety-based disorders: Their usefulness and limitations. In A. Tuma, \& J. Maser (Eds.), Anxiety and the anxiety disorders (pp. 199-244). Hillsdale, NJ: Erlbaum.

Mineka, S., \& Cook, M. (1993). Mechanisms involved in the observational conditioning of fear. Journal of Experimental Psychology, 122, 23-38.

Mineka, S., Davidson, M., Cook, M., \& Keir, R. (1984). Observational conditioning of snake fear in rhesus monkeys. Journal of Abnormal Psychology, 93, 355-372.

Mineka, S., \& Öhman, A. (2002). Phobias and preparedness: The selective, automatic, and encapsulated nature of fear. Biological Psychiatry, 52, 927-937.

Mineka, S., \& Zinbarg, R. (1996). Conditioning and ethological models of anxiety disorders: Stress-in-dynamic-context anxiety models. In D. Hope (Ed.), Perspectives on anxiety, panic, and fear (43rd annual Nebraska symposium on motivation). Lincoln: University of Nebraska Press.

Moses, L. J., Baldwin, D. A., Rosicky, J. G., \& Tidball, G. (2001). Evidence for referential understanding in the emotions domain at twelve and eighteen months. Child Development, 72, 718-735.

Mumme, D. L., Fernald, A., \& Herrera, C. (1996). Infant's responses to facial and vocal emotional signals in a social referencing paradigm. Child Development, 67, 3219-3237.

Muris, P., Bodden, D., Merckelbach, H., Ollendick, T. H., \& King, N. (2003). Fear of the beast: A prospective study on the effects of negative information on childhood fear. Behaviour Research and Therapy, 41, 195-208.

Muris, P., \& Merckelbach, H. (2001). The etiology of childhood specific phobia: A multifactorial model. In M. W. Vasey, \& M. R. Dadds (Eds.), The developmental psychopathology of anxiety (pp. 355-385). New York: Oxford University Press.

Muris, P., Steerneman, P., Merckelbach, H., \& Meesters, C. (1996). The role of parental fearfulness and modeling in children's fears. Behaviour Research and Therapy, 34, 265-268.

Murray, L., Cooper, P. J., de Rosnay, M., Pearson, J., \& Sack, C. (in press). Intergenerational transmission of maternal social anxiety: The role of social referencing processes. Child Development.

Neal, J. A., Edelmann, R. J., \& Glachan, M. (2002). Behavioral inhibition and symptoms of anxiety and depression: Is there a specific relationship with social phobia. British Journal of Clinical Psychology, 41, 361-374.

Öhman, A. (1979). Fear relevance, autonomic conditioning, and phobias: A laboratory model. In P.-O. Sjöden, S. Bates, \& W. S. Dockens III (Eds.), Trends in behavior therapy (pp. 107-134). New York: Academic Press.

Öhman, A. (1986). Face the beast and fear the face: Animal and social fears as prototypes for evolutionary analyses of emotion. Psychophysiology, 23, 123-145.

Öhman, A. (1993). Stimulus prepotency and fear learning: Data and theory. In N. Birbaumer, \& A. Öhman (Eds.), The structure of emotion: Psychophysiological, cognitive, and clinical aspects (pp. 218-239). Seattle, WA: Hogrefe \& Huber.

Öhman, A., Dimberg, U., \& Öst, L.-G. (1985). Biological constraints on the learned fear response. In S. Reiss, \& R. Bootzin (Eds.), Theoretical issues in behavior therapy (pp. 123-175). New York: Academic.

Öhman, A., Eriksson, A., \& Olofsson, C. (1975). One-trial learning and superior resistance to extinction of autonomic responses conditioned to potentially phobic stimuli. Journal of Comparative and Physiological Psychology, 88, 619-627.

Öhman, A., Fredrikson, M., Hugdahl, K., \& Rimmö, P.-A. (1976). The premise of equipotentiality in human classical conditioning: Conditioned electrodermal responses to potentially phobic stimuli. Journal of Experimental Psychology: General, 105, 313-337.

Öhman, A., Hamm, A., \& Hugdahl, K. (2000). Cognition and the autonomic nervous system: Orienting, anticipation, and conditioning. In J. T. Cacioppo, L. G. Tassinary, \& G. G. Berntson (Eds.), Handbook of Psychophysiology (pp. 522-575). New York: Cambridge University Press.

Öhman, A., \& Mineka, S. (2001). Fears, phobias, and preparedness: Toward an evolved module of fear and fear learning. Psychological Review, 108, 483-522.

Ollendick, T. H., \& King, N. J. (1991). Origins of childhood fears: An evaluation of Rachman's theory of fear acquisition. Behaviour Research and Therapy, 29, 117-123.

Öst, L. G. (1987). Age of onset in different phobias. Journal of Abnormal Psychology, 96, 223-229.

Öst, L. G., \& Hugdahl, K. (1981). Acquisition of phobias and anxiety response pattern in clinical patients. Behaviour Research and Therapy, 19, 439-447.

Pedlow, R., Sanson, A., Prior, M., \& Oberklaid, F. (1993). Stability of maternally reported temperament from infancy to 8 years. Developmental Psychology, 29, 998-1007.

Pine, D. S., Klein, R. G., Mannuzza, S., Moulton, J. L., Lissek, S., Guardino, M., et al. (2005). Face-emotion processing in offspring at risk for panic disorder. Journal of the American Academy of Child and Adolescent Psychiatry, 44, 664-672.

Prior, M., Sanson, A., Oberklaid, F., \& Northam, E. (1987). Measurement of temperament in one to three year old children. International Journal of Behavioral Development, 10, 121-132.

Prior, M., Smart, D., Sanson, A., \& Oberklaid, F. (2000). Pathways from infancy to adolescence: Australian Temperament Project 1983-2000. Melbourne: Australian Institute of Family Studies.

Rachman, S. (1977). The conditioning theory of fear acquisition: A critical examination. Behaviour Research and Therapy, 15, 375387.

Rachman, S. (1991). Neoconditioning and the classical theory of fear acquisition. Clinical Psychology Review, 17, 47-67. 
Rapee, R. M. (2001). The development of generalized anxiety disorder. In M. W. Vasey, \& M. R. Dadds (Eds.), The developmental psychopathology of anxiety (pp. 481-503). New York: Oxford University Press.

Rapee, R. M., \& Spence, S. H. (2004). The etiology of social phobia: Empirical evidence and an initial model. Clinical Psychology Review, 24, 737-767.

Repacholi, B. M. (1998). Infant's use of attentional cues to identify the referent of another person's emotional expression. Developmental Psychology, 34, 1017-1025.

Reznick, J. S., Kagan, J., Snidman, N., Gersten, M., Baak, K., \& Rosenberg, A. (1986). Inhibited and uninhibited children: A follow-up study. Child Development, 57, 660-680.

Rosen, W. D., Adamson, L. B., \& Bakeman, R. (1992). An experimental investigation of infant social referencing: Mothers' messages and gender differences. Developmental Psychology, $28,1172-1178$.

Sawchuk, C. N., Lohr, J. M., Westendorf, D. H., Meunier, S. A., \& Tolin, D. F. (2002). Emotional responding to fearful and disgusting stimuli in specific phobics. Behaviour Research and Therapy, 40, 1031-1046.

Seligman, M. E. P. (1971). Phobias and preparedness. Behavior Therapy, 2, 307-320.
Sewell, J., Oberklaid, F., Prior, M., Sanson, A., \& Kyrios, M. (1988). Temperament in Australian toddlers. Australian Pediatric Journal, 24, 343-345.

Shrout, P. E., \& Fleiss, J. L. (1979). Intraclass correlations: Uses in assessing rater reliability. Psychological Bulletin, 86, 420-428.

Siegler, R., DeLoache, J., \& Eisenberg, N. (2003). How children develop. New York: Worth.

Thunberg, M., \& Dimberg, U. (2000). Gender differences in facial reactions to fear-relevant stimuli. Journal of Nonverbal Behavior, 24, 45-51.

Verhulst, F. C., Van der Ende, J., Ferdinand, R. F., \& Kasius, M. C. (1997). The prevalence of DSM-III-R diagnoses in a national sample of Dutch adolescents. Archives of General Psychiatry, 54, 329-336.

Watt, M. C., \& Stewart, S. H. (2000). Anxiety sensitivity mediates the relationships between childhood learning experiences and elevated hypochondriacal concerns in young adulthood. Journal of Psychosomatic Research, 49, 107-118.

Watt, M. C., Stewart, S. H., \& Cox, B. J. (1998). A retrospective study of the learning history origins of anxiety sensitivity. Behaviour Research and Therapy, 36, 505-525.

Weems, C. F., \& Stickle, T. R. (2005). Anxiety disorders in childhood: Casting a nomological net. Clinical Child and Family Psychology Review, 8, 107-134. 